\title{
Change in Iris Dimensions as a Potential Human Consciousness Level Indicator
}

\author{
Pankaj Bhambri, Vijay Kumar Sinha, Meenakshi Jaiswal
}

\begin{abstract}
Detection of human consciousness is vital for validating a legal or official statement whether in the form of written or verbal. A statement given under unconsciousness state is considered null and void as the person is not fully awarded about the consequences of the statement. Several factors affects human consciousness like effect of alcohol, drowsiness, effect of anesthesia, sleeping pills, natural sleeping hours etc. The present available methods for detection of level of consciousness works in a specific condition only. For instance Alcohol Meter can detect the level of alcohol in the breath but not the effects sleeping pills or partial conscious due to drowsiness. In this research we propose a new technique which can detect all types of unconsciousness irrespective of reasons. We used the feature of iris light sensitivity which dilates inversely to pupil. Consciousness and iris dilation is directly proportional i.e. iris dilation increases with increase of consciousness and decreases with decrease of consciousness. We tested this method on 66 volunteers with 99.83\% accuracy for $0.03 \mathrm{~mm}$ iris dilation threshold value unconscious under alcohol effect and under drossiness conditions. Results shows that iris sensitivity decreases significantly during unconscious state, for any reasons. This feature can be used for validation of contracts before signing legal contracts.
\end{abstract}

Index Terms: Consciousness, Iris Dilation, Pupil Dilation, Pupiliometer, ADHAR, Drowsiness, consent, legal contract, Lux, Luminance

\section{INTRODUCTION}

Among all biometric system the Iris recognition system is considered as most robust, hard to duplicate and the most secure system of authentication [1]. However the scammers / criminals can misuse the existing system either by making fake iris images or present a user in front of iris scanner to unlock their account. The present available iris security algorithms fail to detect a forced authentication which might be misused by criminals to unlock the user's account. In this paper we successfully developed an algorithm to examine the conditions in which a real user is forcibly presented in front of iris scanner on gun point to unlock the account. In this case a significant difference can be noticed in the area of iris visibility with respect to user's normal iris area visibility. An abnormal eye blink is also detected in forced condition. We successfully design and developed an algorithm to detect

Revised Manuscript Received on June 15, 2019 \}

Dr. PankajBhambri, Assistant Professor,

Department of Information Technology,

Guru Nanak Dev Engineering College, Ludhiana (Punjab), India. pkbhambri@gndec.ac.in

Vijay Kumar Sinha, Associate Professor,

Research Scholar IKGPTU, Department of CSE, Chandigarh Engineering College, Landran, Mohali (Punjab), India. cecm.cse.vk@gmail.com

Ms. MeenakshiJaiswal, Assistant Professor

Chandigarh Engineering College, Landran, Mohali (Punjab), India. meenakshi.1233@cgc.edu.in such conditions to protect the users from criminals.For over 15 years liveness location has been an imperative component of worldwide dialog on biometric security [2-5]. As indicated by ISO/IEC, it concerns 'recognition of anatomical attributes or automatic or willful responses, with a specific end goal to decide whether a biometric test is being caught from a living subject present at the purpose of catch. The capacity to check the liveness is significant to any biometric sensor. Indeed,word for managing living and bona fide organic attributes, and not with nonliving ancient rarities. Once the biometric sensor acknowledges relics or non-living body parts, the whole framework conveying such sensor ends up plainly unsettled.For over a century researchers have realized that our eyes' students react to more than changes in light. They additionally deceive mental and enthusiastic upheaval. Indeed, understudy widening associates with excitement so reliably that specialists utilize student estimate, or pupillometry, to examine an extensive variety of mental marvels. What's more, they do this without knowing precisely why our eyes carry on along these lines."No one truly knows for beyond any doubt what these progressions do," says Stuart Steinhauer, chief of the Biometrics Research Lab at the University Of Pittsburgh School Of Medicine. He sees the enlargements as a result of the sensory system handling vital data.

The visual cortex in the back of the mind collects the real pictures we see. In any case, an alternate, more established piece of the sensory system - the autonomic - deals with the nonstop tuning of student measure (alongside other automatic capacities, for example, heart rate and sweat). In particular, it directs the development of the iris to control the measure of light that enters the eye, like a camera gap. The iris is made of two kinds of muscle: a ring of sphincter muscles that enclose and contract the student down to two or three millimeters crosswise over to keep excessively light from entering; and an arrangement of dilator muscles laid out like bike spokes that can extend the understudy up to eight millimeters - roughly the breadth of a chickpea-in low light.

Incitement of the autonomic sensory system's thoughtful branch, known for activating "battle or flight" reactions when the body is under pressure, actuates student widening. Though incitement of the parasympathetic framework, known for "rest and process" capacities, causes narrowing. Hindrance of the last framework can in this way additionally because widening. The measure of the understudies at any given time mirrors the adjust of these powers acting all the while.

The understudy reaction to intellectual and enthusiastic occasions happens on a much

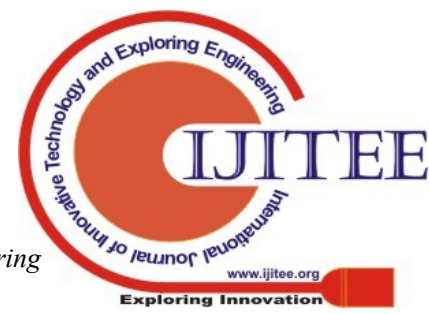


littler scale than the light reflex, with changes for the most part not as much as a large portion of a millimeter. By recording subjects' eyes with infrared cameras and controlling elements that may influence student estimate, for example, encompassing brilliance, shading and separation, researchers can utilize understudy developments as an intermediary for different procedures, as mental strain.different procedures, as mental strain.

Princeton University therapist Daniel Kahneman demonstrated quite a few years back that understudy estimate increments in extent to the trouble of a job needing to be done. Compute nine times 13 and your understudies will enlarge marginally. Attempt 29 times 13 and they will broaden further and remain enlarged until the point that you achieve the appropriate response or quit attempting. Kahneman says in his book, Thinking Fast and Slow that he could divine when somebody abandoned a duplication issue just by looking for understudy withdrawal amid the examination.

"The understudies mirror the degree of mental exertion in a staggeringly exact way," Kahneman said in a meeting with the German news magazine Der Spiegel, including, "I have never done any work in which the estimation is so exact." When he taught subjects to recollect and recount a progression of seven digits, their students developed relentlessly as the numbers were introduced one by one and contracted consistently as they emptied the digits from memory.

Ensuing exploration found that the understudies of more shrewd individuals (as characterized by their Scholastic Aptitude Test scores) enlarged less because of intellectual undertakings contrasted and those of lower-scoring members, showing more effective utilization of mental ability.

\section{EARLY WORKS IN IRIS SECURITY:}

The authors in [6] accumulated his own particular iris motivate contraption to select understudy evaluate changes under unmistakable light stuns, each insight is changed over into a segment space portrayed by Kohn and Clynes understudy development indicate parameters and later Support vector machine (SVM) is utilized to sort out normal response and unconstrained developments. Red eye influence is the ordinary appearance of red understudies in shading photos of eyes. It happens when we utilize a photographic burst near the camera purpose of union in enveloping low light. This will be showed up by people and of creatures as they contain tapetumlucidum. The key reason of the red shading is the plentiful measure of blood in the choroid which supports the back of the eye and is organized behind the retina.

Purkinje pictures are impressions of things from the structure of the eye. Standard human eye has four optical surfaces; each of them reflects impressive lights: the front and back surface of the cornea, and the front and back surface of the purpose of merging. For this situation, the four reflected pictures of occasion light on each optical surface are called as Purkinje pictures. The spots of these four Purkinje responses rely on the geometry of the light sources. In his paper [7] found the theoretical positions and separations between the Purkinje pictures in context of the human eye show up in their examination. Since the fundamental three Purkinje pictures (to begin with, second and third) are framed by reflecting from a raised mirror, pictures are virtual and erect. By the by, the last Purkinje picture (fourth) is affirmed and vexed as it is molded by reflecting from an inside mirror. From that, the correct spots of Purkinje pictures can be perceived with the exception of the turmoil by eyebrows, and so on.

Contemplating the quality highlights, authors in [8] proposed a liveness unmistakable evidence structure in light of a blueprint of picture quality related features. In the fundamental propel the iris is apportioned from the foundation by utilizing a circuitous Hough change with a specific extreme goal to perceive the iris and understudy boundaries. It is common that the level of progression of an iris engraved on a sheet of paper and held before a sensor will differentiate from that of an ensured eye where an all the all the all the more proceeding with position can be remained mindful of the target that the little tremble found in the key case ought to be tolerably dubious. Distinctive iris picture quality highlights including center highlights, advancement highlights, impediment highlights, neighboring and general partition, understudy widening are converged to produce a high dimensional segment vector for demand of extortion and good old fashioned iris pictures. Pupil's Sequential Floating Feature Selection (SFFS) figuring is utilized as highlight choice approach as it has a not all that terrible execution emerged from different frameworks. Basing in travel that understudy evaluate changes under unmistakable light stuns, values are enlisted basing on the unconstrained understudy developments and its response after a sudden expansion of the vitality of the noticeable light.

Those promising, yet single picture, properties were later used commonly to outline multidimensional, picture quality-based liveness markers. The authors in [9] apply incorporate assurance way to deal with find the best mix of liveness features among 22 proposed essential iris geometrical or repeat descriptors. Incidentally, mixing particular quality covariates has high potential and it was associated later by [10] nearby quadratic discriminant examination to distinguish $99.75 \%$ of iris printouts, in the meantime deceptively expelling $4.2 \%$ of the sound eyes. Researchers have since utilized pupillometry to evaluate everything from drowsiness, contemplation and sexual enthusiasm to race inclination, schizophrenia, moral judgment, extreme introvertedness and melancholy. What's more, while they haven't been understanding individuals' musings essentially, they've come quite close.

"Understudy enlargement can deceive a person's choice before it is transparently uncovered," finished up a recent report drove by Wolfgang Einhäuser-Treyer, a neurophysicist at Philipps University Marburg in Germany. Members were advised to press a catch anytime amid a 10 -second interim, and their understudy sizes related with the planning of their choices. Enlargement started around one moment before they squeezed the catch and crested one to two seconds after [11].

However, are understudies enlightening outside the lab? Would pupil be able to estimate be 
utilized to "peruse" a man's aims and sentiments? As indicated by Men's Health magazine a man can tell when it is "an ideal opportunity to make your turn" by watching his date's students, yet some wariness is justified. "It is vague to me to what degree this can be misused in totally over the top settings," Einhäuser-Treyer wrote in an email, bringing up that light conditions could without much of a stretch meddle with beginner endeavors at relational pupillometry.

Different endeavors to abuse student expansions for purposes past logical research have fizzled. Amid the Cold War, Canadian government authorities attempted to build up a gadget they called the "natural product machine" to distinguish homosexuality among common administration representatives by estimating how the students in their eyes reacted to scandalous pictures of ladies and men. The machine, which never worked, was to help the administration's cleanse of gay men and lesbians from the common administration and in this manner purportedly lessen defenselessness to Soviet extortion [13].

A student test for sexual introduction stays as impossible as it was in the 1960s. Analysts at Cornell University as of late demonstrated that sexual introduction connected with student expansion to suggestive recordings of their favored sex, however just by and large and just for male subjects. In spite of the fact that pupillometry indicates guarantee as a noninvasive measure of sexual reaction, they finished up, "only one out of every odd member's sexual introduction was effectively characterized" and "a noticeable measure of changeability in student widening was irrelevant to the member's sexual introduction."

Pupillometry additionally wound up well known in the promoting business amid the 1970 s as an approach to test purchasers' reactions to TV ads, says JagdishSheth, an advertising educator at Emory University. Be that as it may, the training was in the long run surrendered. "There was no logical method to build up whether it gauged intrigue or uneasiness," Sheth says [15].

Regardless of these impediments, pupillometry is an important instrument for mental research, says Pittsburgh's Steinhauer, on the grounds that our eyes are anything but difficult to see and in addition give a delicate pointer of intellectual, enthusiastic and tactile reaction. "It resembles having an anode for all time embedded in the mind," he says. "And whatever we can do is watch the change toward the end. We can't screen everything going into it."

The understudies enlarge for some reasons. They for the most part change their size with the power of light: understudies end up littler when the light is brilliant, while oblivious, students enlarge. In the event that expanded students don't come about because of an ordinary reaction to low light, along these lines they might be caused by restorative prescriptions or drugs, organic or substance poisons and toxins and infections including the anxious system. In expansion, enlarged understudies may come about because of physiological jolts, for example, fear, yet as a rule, such response isn't clear and the normally instigated reason, dread can be the wellspring of widened student will turn out to be marginally more enlarged briefly. It is conceivable to get expanded students in view of dread. It is described by the adjustments in the measure of the student. As a students, in spite of the fact that widened student isn't a genuine medical issue, you should analyze and treat it expeditiously to find out the fundamental causes and avert creating different issues [16].

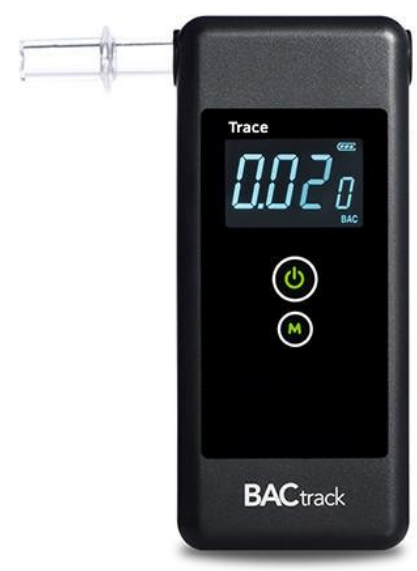

Fig 1 Digital Breathalyzer for estimating blood alcohol content

Liveness location alludes to the identification of living indications, and henceforth is an uncommon instance of a more extensive class of procedures going for discovery of any introduction assault. ISO/IEC characterizes the introduction assault as 'introduction of a curio or human trademark to the biometric catch subsystem in a manner that could meddle with the planned strategy of the biometric framework'. This implies any subversive activity (i.e., with the goal to subvert a biometric framework) ought to be distinguished as an introduction assault. Notwithstanding, the goal of the aggressor can't be construed. Consequently the introduction assault turns into an extremely wide running field that incorporates introduction of phony items, and additionally dead body parts, mixed up or pressured introductions, and even zero-exertion impostor endeavors. This obscure goal additionally causes false alerts by arranging some suspicious activities as potential introduction assaults, non-conformant introduction because of sickness, weakness or introduction of manufactured articles for corrective or wellbeing reasons. This entangles the arrangement of assaults and empowers on-going logical talk in the field of how to effectively manage introduction assault location [17].

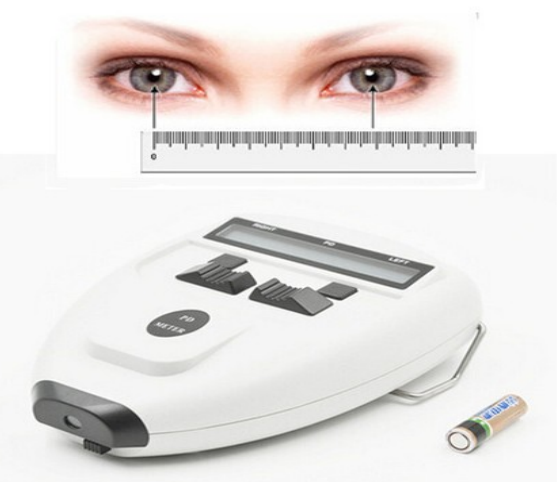

Fig 2 Optical Digital Pupilometer

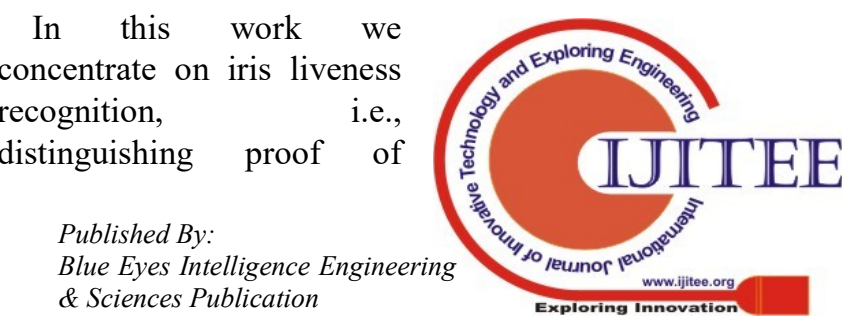


liveness indications that could demonstrate the credibility of the eye and the readiness of the subject to be enrolled by the sensor. Rather than all the more generally utilized static properties of the eye or its tissue, we utilize flow of the iris enrolled under obvious light boosts. Since the iris responds automatically when the light power transforms, it is hard to disguise this wonder. As will be appeared in the paper, the iris elements are not paltry, making it hard to emulate them for counterfeit articles. In our tests we chose not to utilize static protests, for example, iris paper printouts or designed contact focal points, since in such cases we would be guaranteed of progress ( static items don't present huge elements, aside from some estimation clamor, and along these lines are effortlessly unmistakable when flow is the key). Rather, to survey the proposed strategy execution, we group unconstrained iris motions and typical iris responses to a positive surge of obvious light, in this manner making the tests more sensible. To our best information, this is the main work that utilizes iris progression for liveness location and which is assessed on powerful, genuine questions as opposed to static antiquities [8].

Dilated pupils can occur with any type of anxiety, but are most common during periods of intense anxiety that occur in the following conditions:

- Panic Disorder/Panic Attacks

- PTSD

- Phobias

Although it may occur during any period of severe anxiety.

Normally, when the fight or flight response is functioning properly, it should only activate during periods of intense fear - i.e., times when you will need to fight or run away. During those times, your body needs to have the best vision possible.

That is why your pupils dilate. When they dilate, your eyes are letting in more light and your vision temporarily improves.

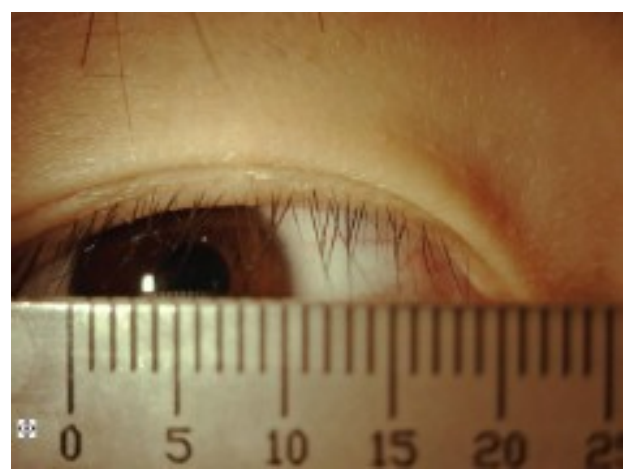

Fig3 Measurement of Iris

The paper is sorted out as take after: Section II gives a short synopsis of mistake measurements utilized as a part of the paper. Area III quotes and arranges the most vital past work on PAD identified with iris acknowledgment. Segment IV portrays a database of eye motion pictures gathered for this exploration [18].

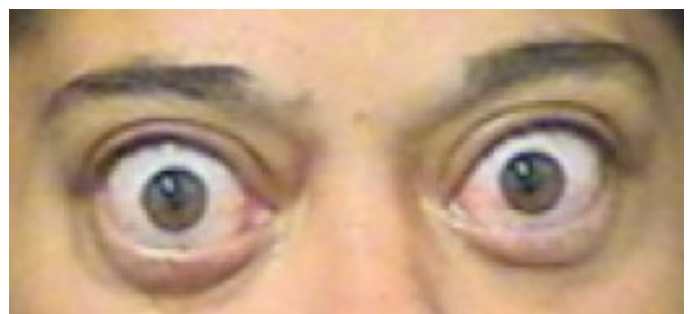

Fig 4 Iris dilation under Alcohol; (Extra Widen)

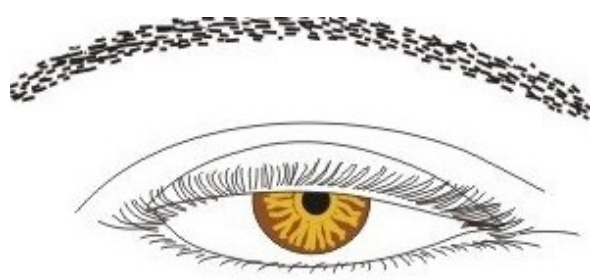

Drowsy Eye

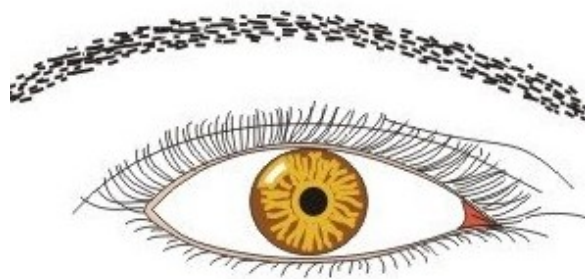

Conscious Eye

Fig.5 Shading of Iris area during drowsiness

\section{RECOGNITION OF PUPIL DYNAMICS}

\section{A. Information pre-preparing}

The authors in [11] described Pupil location, division and figuring of its size: Pupil progression is communicated by changes of its size. The understudy measure is however a loose and general measurement that might be ascertained in different ways. In this work we chose to utilize the most widely recognized, round estimate of its - perhaps unpredictable - shape. This is done purposefully because of three factors: a) rapid of round division, b) ordinariness of roundabout displaying in as of now conveyed iris acknowledgment strategies, and c) irrelevance of non roundabout deviations while portraying the elements [19].

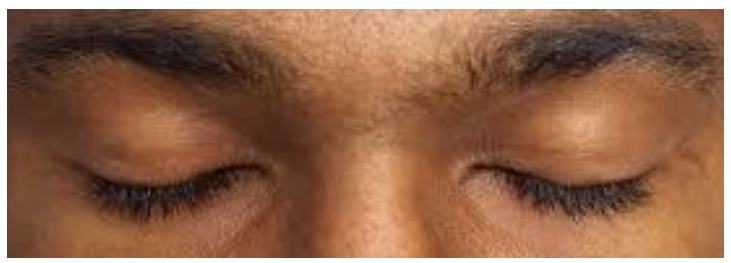

Fig. 6 Eye fatigue is a major cause for road accidents 


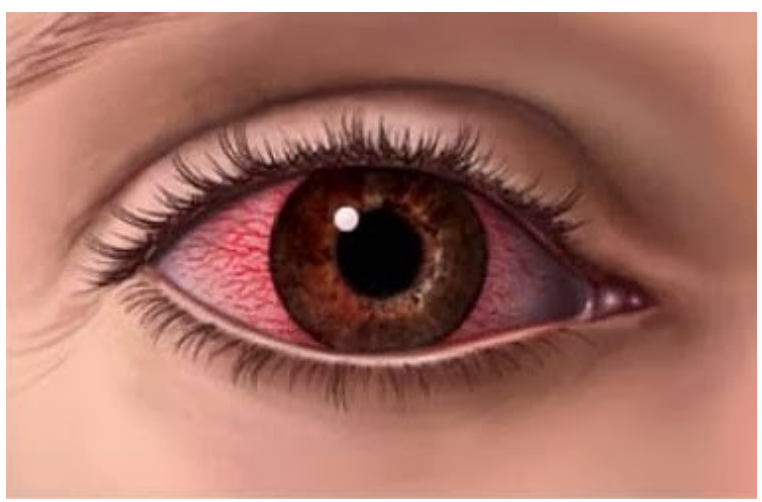

Fig. 7 A fatigue eye

Having no ground truth identified with iris area, we distinguish and confine the student in each casing autonomously. While discovery alludes to an announcement of whether the student exists inside the casing, the limitation conveys its position. To limit a limit between the understudy and the iris, we connected a Hough change working on directional picture (estimation of a picture inclination conveying both a slope esteem and its course). We parameterized the change to make it touchy to dull round shapes and practically lethargic to other dim shapes and light circles, for example, specular reflections. Utilization of slope and affectability to roundabout shapes makes this technique shockingly strong regardless of the possibility that the understudy is half secured by eyelids. Therefore each eye film is changed into a period arrangement of understudy radii, we don't utilize inclination esteems that don't surpass a base limit (set tentatively to the equipment setup that we utilized). On the off chance that there is no single slope esteem surpassing the edge, the strategy reports that no understudy could be recognized. The last acknowledges understudy recognition, and recognizes time minutes when the eye is totally secured by eyelids [20].

Artifacts expulsion: Raw groupings of understudy radii are not impeccable because of division mistake. By and large, we experience two sorts of disturbances: an) understudy recognition blunders (regularly because of flickers completely covering the eye), and b) student division commotion (commonly because of squints in which the student is somewhat secured, eye movement, off-hub look, very noncircular understudy shape that outcomes in little motions of the. Understudy estimate (dark dabs) measured consequently amid a solitary test under the light jolts (blue strong line). Note that catch of a genuine question brings about a non-perfect succession of understudy estimate because of flickers (dark specks withdrawing from the normal arrangement), eye conclusion (red dabs of zero ordinate signifying that no student is identified), or changes of the division procedure (uncovering as a 'clamor' in the grouping). Outlining models are appeared at the best and connected to the relating snapshots of the succession [21].

Blunders of the main kind are distinguished by the student identification process. Those wrong focuses can be effectively discarded when demonstrating the student progression (set apart as red dabs lying on the even hub.

\begin{tabular}{|c|c|c|}
\hline $\begin{array}{c}\text { Size of Iris in } \\
\text { Normal } \\
\text { Condition (mm) }\end{array}$ & $\begin{array}{c}\text { Size of Iris under } \\
\text { Alcohol Effect } \\
(\mathrm{mm}) \\
\text { Quantity } 200 \mathrm{ml} \\
\text { (Alcohal 40\%) }\end{array}$ & $\begin{array}{c}\text { Difference } \\
(\mathrm{mm})\end{array}$ \\
\hline (A) & (B) & $(\mathbf{B}-\mathbf{A})$ \\
\hline 10.21 & 12.4 & 2.19 \\
\hline 10.31 & 12.7 & 2.39 \\
\hline 10.11 & 13.2 & 3.09 \\
\hline 10.41 & 12.3 & 1.89 \\
\hline 10.51 & 12.6 & 2.09 \\
\hline 11.11 & 13.2 & 2.09 \\
\hline 10.91 & 13.4 & 2.49 \\
\hline 10.71 & 13.5 & 2.79 \\
\hline 10.61 & 12.8 & 2.19 \\
\hline 11.21 & 12.6 & 1.39 \\
\hline 11.31 & 13.2 & 1.89 \\
\hline 10.41 & 13.4 & 2.99 \\
\hline 10.51 & 12.3 & 1.79 \\
\hline 11.21 & 12.5 & 1.29 \\
\hline 10.91 & 13.2 & 2.29 \\
\hline 10.51 & 13.4 & 2.89 \\
\hline 10.21 & 13.5 & 3.29 \\
\hline 10.31 & 13.2 & 2.89 \\
\hline 10.11 & 12.3 & 2.19 \\
\hline 10.41 & 12.6 & 2.19 \\
\hline 10.61 & 13.2 & 2.59 \\
\hline 11.21 & 12.3 & 1.09 \\
\hline 11.31 & 12.6 & 1.29 \\
\hline 10.41 & 13.2 & 2.79 \\
\hline 10.51 & 13.4 & 2.89 \\
\hline 11.21 & 13.5 & 2.29 \\
\hline 10.61 & 12.8 & 2.19 \\
\hline 10.51 & 12.6 & 2.09 \\
\hline 10.21 & 13.2 & 2.99 \\
\hline 11.21 & 13.4 & 2.19 \\
\hline 11.31 & 12.3 & 0.99 \\
\hline 10.41 & 12.5 & 2.09 \\
\hline 10.51 & 13.2 & 2.69 \\
\hline 11.21 & 13.4 & 2.19 \\
\hline 10.61 & 13.5 & 2.89 \\
\hline 11.21 & 13.2 & 1.99 \\
\hline 11.31 & 13.4 & 2.09 \\
\hline 10.41 & 13.5 & 3.09 \\
\hline 10.51 & 13.7 & 3.19 \\
\hline 11.21 & 12.3 & 1.09 \\
\hline 10.61 & 12.6 & 1.99 \\
\hline 11.31 & 13.2 & 1.89 \\
\hline 10.41 & 12.3 & 1.89 \\
\hline 10.51 & 12.6 & 2.09 \\
\hline 11.21 & 13.2 & 1.99 \\
\hline 10.61 & 13.4 & 2.79 \\
\hline 11.21 & 13.5 & 2.29 \\
\hline 11.31 & 12.8 & 1.49 \\
\hline 10.41 & 12.3 & 1.89 \\
\hline
\end{tabular}




\begin{tabular}{|l|c|l|}
\hline 10.51 & 12.6 & 2.09 \\
\hline 11.21 & 13.2 & 1.99 \\
\hline 10.61 & 12.3 & 1.69 \\
\hline 11.31 & 12.6 & 1.29 \\
\hline 10.41 & 13.2 & 2.79 \\
\hline 11.31 & 13.4 & 2.09 \\
\hline 10.41 & 13.5 & 3.09 \\
\hline 10.51 & 12.8 & 2.29 \\
\hline 11.21 & 12.6 & 1.39 \\
\hline 10.61 & 13.2 & 2.59 \\
\hline 11.21 & 13.4 & 2.19 \\
\hline 11.31 & 12.3 & 0.99 \\
\hline 10.41 & 12.5 & 2.09 \\
\hline 10.51 & 13.2 & 2.69 \\
\hline 11.21 & 13.4 & 2.19 \\
\hline 10.61 & 13.5 & 2.89 \\
\hline 10.89 & 13.85 & 2.96 \\
\hline 10.76 & 12.97 & 2.21 \\
\hline & &
\end{tabular}

\section{Size of Iris under Alcohol Effect}

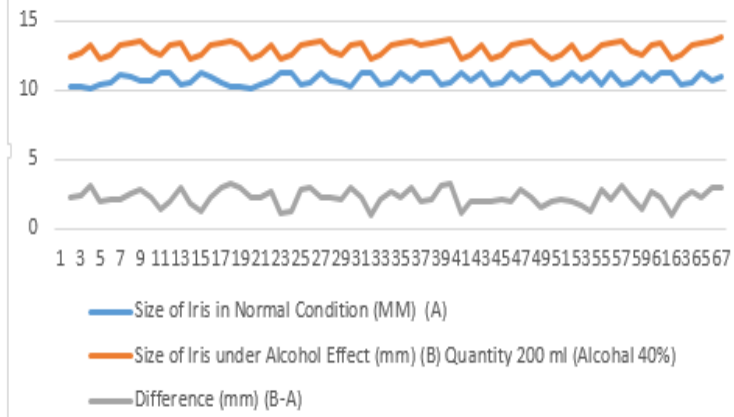

Fig. 7 A fatigue eye

Nonetheless, the division blunders can be distinguished just to some degree when the student span separates fundamentally when contrasted with its neighboring esteems. These sudden falls in understudy sweep are for the most part caused by incomplete squints and - because of the speed of flicker with respect to 25 outlines for each second - they ordinarily possess a few (or even separated) values. We along these lines connected a middle sifting with one moment skyline connected as a sliding window [22], [23].

\section{B. Displaying of understudy progression}

Light force surges produce clear student tightening and enlargement. Kohn and Clynes saw an asymmetry in understudy reaction relying upon whether the blaze is sure (from haziness to splendor) or negative, and proposed a response show that can be graphically imagined as a two-channel exchange capacity of a mind boggling contention.Understudy progression display conveyed in this work and got from a unique proposition of Kohn and Clynes. Diagram republished from [24]. The upper channel comprises of a moment arrange dormancy with time constants $\mathrm{T} 1$ and $\mathrm{T} 2$, and a slack component described by $\tau 1$. It demonstrates a transient conduct of the student just for positive light boosts, what is ensured by a nonlinear capacity put after the Slack component and chopping down the channel reaction for negative jolts. The channel pick up is controlled by Kr. Thus, the lower channel is in charge of displaying long haul and determined changes in understudy size, and replies by setting another student range after both the negative or positive light jolts [25].

\section{Table 2: Iris measurement of drowsy eyes}

\begin{tabular}{|c|c|c|c|}
\hline & $\begin{array}{l}\text { Size of Iris in } \\
\text { Normal } \\
\text { Condition } \\
\text { (mm) }\end{array}$ & $\begin{array}{l}\text { Size of Iris } \\
\text { during } \\
\text { Drowsiness } \\
\text { (mm) }\end{array}$ & $\begin{array}{l}\text { Difference } \\
\quad(\mathrm{mm})\end{array}$ \\
\hline S no. & (A) & (B) & $(\mathrm{B}-\mathrm{A})$ \\
\hline 1 & 10.21 & 12.2 & 1.99 \\
\hline 2 & 10.31 & 12.5 & 2.19 \\
\hline 3 & 10.11 & 13.1 & 2.99 \\
\hline 4 & 10.41 & 12.2 & 1.79 \\
\hline 5 & 10.51 & 12.5 & 1.99 \\
\hline 6 & 11.11 & 13.1 & 1.99 \\
\hline 7 & 10.91 & 13.3 & 2.39 \\
\hline 8 & 10.71 & 13.4 & 2.69 \\
\hline 9 & 10.61 & 12.7 & 2.09 \\
\hline 10 & 11.21 & 12.5 & 1.29 \\
\hline 11 & 11.31 & 13.1 & 1.79 \\
\hline 12 & 10.41 & 13.3 & 2.89 \\
\hline 13 & 10.51 & 12.2 & 1.69 \\
\hline 14 & 11.21 & 12.4 & 1.19 \\
\hline 15 & 10.91 & 13.1 & 2.19 \\
\hline 16 & 10.51 & 13.3 & 2.79 \\
\hline 17 & 10.21 & 13.4 & 3.19 \\
\hline 18 & 10.31 & 13.1 & 2.79 \\
\hline 19 & 10.11 & 12.2 & 2.09 \\
\hline 20 & 10.41 & 12.5 & 2.09 \\
\hline 21 & 10.61 & 13.1 & 2.49 \\
\hline 22 & 11.21 & 12.2 & 0.99 \\
\hline 23 & 11.31 & 12.5 & 1.19 \\
\hline 24 & 10.41 & 13.1 & 2.69 \\
\hline 25 & 10.51 & 13.3 & 2.79 \\
\hline 26 & 11.21 & 13.4 & 2.19 \\
\hline 27 & 10.61 & 12.7 & 2.09 \\
\hline 28 & 10.51 & 12.5 & 1.99 \\
\hline 29 & 10.21 & 13.1 & 2.89 \\
\hline 30 & 11.21 & 13.3 & 2.09 \\
\hline 31 & 11.31 & 12.2 & 0.89 \\
\hline 32 & 10.41 & 12.4 & 1.99 \\
\hline 33 & 10.51 & 13.1 & 2.59 \\
\hline 34 & 11.21 & 13.3 & 2.09 \\
\hline 35 & 10.61 & 13.4 & 2.79 \\
\hline 36 & 11.21 & 13.1 & 1.89 \\
\hline 37 & 11.31 & 13.3 & 1.99 \\
\hline 38 & 10.41 & 13.4 & 2.99 \\
\hline 39 & 10.51 & 13.6 & 3.09 \\
\hline 40 & 11.21 & 12.2 & 0.99 \\
\hline 41 & 10.61 & 12.5 & 1.89 \\
\hline 42 & 11.31 & 13.1 & 1.79 \\
\hline 43 & 10.41 & 12.2 & 1.79 \\
\hline 44 & 10.51 & 12.5 & 1.99 \\
\hline 45 & 11.21 & 13.1 & 1.89 \\
\hline 46 & 10.61 & 13 & 2.69 \\
\hline
\end{tabular}




\begin{tabular}{|l|l|l|l|}
47 & 11.21 & 13.4 & 2.19 \\
\hline 48 & 11.31 & 12.7 & 1.39 \\
\hline 49 & 10.41 & 12.2 & 1.79 \\
\hline 50 & 10.51 & 12.5 & 1.99 \\
\hline 51 & 11.21 & 13.1 & 1.89 \\
\hline 52 & 10.61 & 12.2 & 1.59 \\
\hline 53 & 11.31 & 12.5 & 1.19 \\
\hline 54 & 10.41 & 13.1 & 2.69 \\
\hline 55 & 11.31 & 13.3 & 1.99 \\
\hline 56 & 10.41 & 13.4 & 2.99 \\
\hline 57 & 10.51 & 12.7 & 2.19 \\
\hline 58 & 11.21 & 12.5 & 1.29 \\
\hline 59 & 10.61 & 13.1 & 2.49 \\
\hline 60 & 11.21 & 13.3 & 2.09 \\
\hline 61 & 11.31 & 12.2 & 0.89 \\
\hline 62 & 10.41 & 12.4 & 1.99 \\
\hline 63 & 10.51 & 13.1 & 2.59 \\
\hline 64 & 11.21 & 13.3 & 2.09 \\
\hline 65 & 10.61 & 13.4 & 2.79 \\
\hline 66 & 10.89 & 12.5 & 1.61 \\
\hline 67 & 10.76 & 12.86 & 2.09 \\
\hline & & & \\
\hline
\end{tabular}

Iris Mesurement during Drowsy Eyes

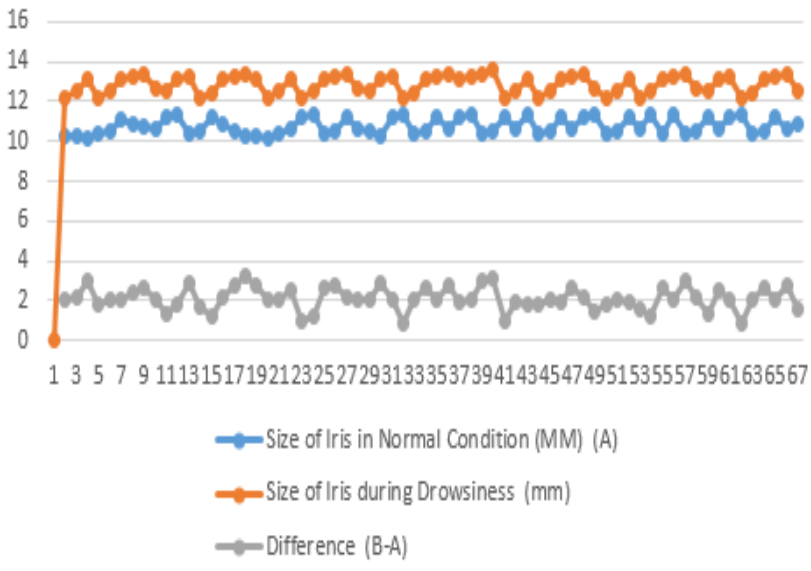

Fig. 8ASize of Iris during Drowsiness

Table 3: Decision making on the basis of Iris sensitivity (Dilation):

\begin{tabular}{|c|c|c|c|c|c|c|c|c|}
\hline $\begin{array}{l}\text { Sl } \\
\text { No. }\end{array}$ & $\begin{array}{l}\text { Iris Images } \\
\text { (Right Iris) }\end{array}$ & $\begin{array}{l}\text { B. Daylight } \\
\text { intensity } \\
\text { Luminance }\end{array}$ & $\begin{array}{ll}\text { Mean } & \text { Iris } \\
\text { Dilation } & \\
\text { value } & \\
\text { (Right } & \text { Iris } \\
\text { ) } & \end{array}$ & $\begin{array}{l}\text { Iris Images } \\
\text { ( Left Iris) }\end{array}$ & $\begin{array}{l}\text { C. Daylight } \\
\text { intensity } \\
\text { Luminance }\end{array}$ & $\begin{array}{ll}\text { Mean } & \text { Iris } \\
\text { Dilation } & \\
\text { value } & \\
\text { (Left } & \text { Iris } \\
\text { ) } & \end{array}$ & \multicolumn{2}{|c|}{$\begin{array}{l}\text { Decision Making } \\
\text { Unconsciousness } \\
\text { Detection } \\
\text { (Both iris) }\end{array}$} \\
\hline 1 & & 2,000 lux & $10.3 \mathrm{~mm}$ & & $2,000 \operatorname{lux}$ & $13.2 \mathrm{~mm}$ & $\begin{array}{l}\text { Norn } \\
\text { Cons }\end{array}$ & $\begin{array}{l}\text { al } \\
\text { iousness }\end{array}$ \\
\hline 2 & & 2,000 lux & $13.2 \mathrm{~mm}$ & & $2,000 \operatorname{lux}$ & $12.9 \mathrm{~mm}$ & Unco & nscious \\
\hline 3 & & 2,000 lux & $12.5 \mathrm{~mm}$ & & 2,000 lux & $12.2 \mathrm{~mm}$ & $\begin{array}{l}\text { Norn } \\
\text { Cons }\end{array}$ & $\begin{array}{l}\text { al } \\
\text { iousness }\end{array}$ \\
\hline 4 & & $2,000 \operatorname{lux}$ & $13.00 \mathrm{~mm}$ & & $2,000 \operatorname{lux}$ & & $\begin{array}{l}13.6 \\
\mathrm{~mm}\end{array}$ & Unconscious \\
\hline
\end{tabular}

\section{RESULT AND DISCUSSIONS:}

We successfully design and developed algorithm based upon feature of iris sensitivity towards light. We used the feature of iris and pupil light sensitivity which dilated inversely to pupil. Consciousness and iris dilation is directly proportional i.e. iris dilation increases with increase of consciousness and decreases with decrease of consciousness. We tested this method on 55 volunteers with $99.83 \%$ accuracy for $0.03 \mathrm{~mm}$ iris dilation threshold value in outdoor day light condition and $0.04 \mathrm{~mm}$ for indoor day time lighting condition. A high sensitive iris (fluctuations range $\sim 0.45-0.98 \mathrm{~mm}$ ) is recorded in normal day light condition (Outdoor); whereas a reduced iris fluctuations recorded for indoor low luminous conditions (fluctuations range $\sim 0.3-0.8 \mathrm{~mm}$ ).

For unconscious conditions the iris sensitivity drops significantly (fluctuations range $\sim 0.41-0.63 \mathrm{~mm}$ ) i.e. iris fluctuates with reduced rate (fluctuations range $\sim 0.58-0.72$ $\mathrm{mm}$ ) in outdoor and (fluctuations range $\sim 0.27-0.29 \mathrm{~mm}$ ). Iris area expands with higher consciousness and shrinks with lower consciousness.

A sample size of 66 volunteers are taken for the observations. Observations

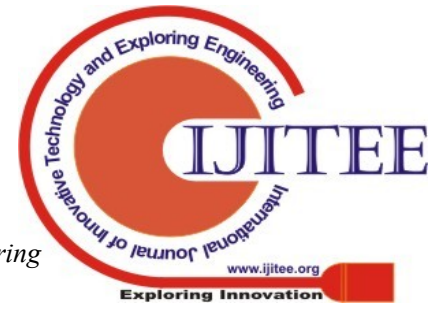


are recorded with the help of digital Pupiliometer. Result are compared with existing available methods of consciousness detection and concluded that this system can be used for all types of unconsciousness with least complexities, rapid result and better accuracies.

\section{FUTURE SCOPE:}

This research work can be extended for consciousness detection for medical purposes viz. In Operation Theater before proceed of surgery. The research can be customized for detection of drunk drivers for accident avoidance. Consciousness detection System can be developed for self-testing before going for driving or during long driving to avoid accidents.

\section{ACKNOWLEDGEMENT}

I first and foremost thanks to IKG Punjab Technical University, Kapurthala, Punjab for providing us this excellent research opportunity. Our hearty thanks to our work place Chandigarh Engineering College, Landan, Mohali and Guru Nanak Dev Engineering College, Ludhiana (Punjab) which facilitates us all essential facilities to conduct this research work. We also thanks to the head of departments Dr. AmitVerma and Dr. Ajay Vasishth for full support and motivation.Last but not least we thanks to Elsevier for providing us a global platform to showcase our research findings.

\section{REFERENCES}

1. Czajka "Pupil dynamics for iris liveness detection" IEEE Trans. Inf. Forensics Security vol. 10 Apr. 2015, pp. 726-735.

2. Czajka and A. Pacut, "Iris Recognition System Based on Zak-Gabor Wavelet Packets," Journal of Telecommunications and Information Technology, no. 4, 2010, pp. 10-18.

3. Czajka, "Database of iris printouts and its application: Development of liveness detection method for iris recognition," in Methods and Models in Automation and Robotics (MMAR), 2013 18th International Conference on, Aug 2013, pp. 28-33.

4. Adam Czajka, (2014), "Pupil dynamics for presentation attack detection in iris recognition," in International Biometric Performance Conference.

5. Biometric Vulnerability Assessment Expert Group (BVAEG). [Online]. Available: http://www.biometricsinstitute.org/pages biometric-vulnerability-assessment-expert-group-bvaeg.html

6. E. C. Lee and K. R. Park, (2010), "Fake iris detection based on 3D structure of iris pattern," International Journal of Imaging Systems and Technology, 2010, pp. 162-166.

7. E. Lee et al., Fake iris detection by using Purkinje image. In Proc. ICB, Hong Kong, China, 2006, pp. 397-403.

8. E. Lee, K. Park, and J. Kim, "Fake iris detection by using purkinje image," in Advances in Biometrics, ser. Lecture Notes in Computer Science, D. Zhang and A. Jain, Eds. Springer Berlin Heidelberg, 3832, 2005, pp. 397-403.

9. EuiChul Lee, Kang Ryoung Park, "Fake Iris detection Based on iris Pattern ", Wiley Periodicals Inc.(2010)

10. EuiChul Lee, Kang Ryoung Park, Jaihie Kim, "Fake Iris Detection by Using Purkinje Image ", Springer, Advances in Biometrics, Vol 3832,2006, pp 397-403.

11. ISO/IEC JTC 1/SC 37 Text of Working Draft 30107-3, "Information Technology - Presentation Attack Detection - Part 3: Testing, reporting and classification of attacks," February 28, 2014.

12. J. Galbally, J. Ortiz-Lopez, J. Fierrez and J. Ortega-Garcia, (2012), "Iris liveness detection based on quality related features," Proc. ICB 2012, pp. 271-276, New Delhi, India, 2012.

13. J. Galbally, S. Marcel, and J. Fierrez, "Image quality assessment for fake biometric detection: Application to iris, fingerprint, and face recognition," Image Processing, IEEE Transactions on, 23, 2, Feb 2014, pp. 710-724

14. J. Galbally, J. Ortiz-Lopez, J. Fierrez, and J. Ortega-Garcia, "Iris liveness detection based on quality related features," in Proc. 5th IAPR ICB, 2012, pp. 271-276.
15. Javier Galbally, SébastienMarcel,JulianFierrez, "Image Quality Assessment for Fake Biometric Detection: Application to Iris, Fingerprint, and Face Recognition.” IEEE Trans. on Image Process, 23, February 2014

16. J. Galbally, R. Cappelli, A. Lumini, G. G. de Rivera, D. Maltoni,J. Fierrez, "An evaluation of direct and indirect attacks using fake fingers generated from ISO templates," Pattern Recognition. Lett., 31,8,2010, pp. $725-732$.

17. J. Daugman, "Countermeasures against subterfuge," in Biometrics: Personal Identication in Networked Society, Jain, Bolle, and Pankanti, Eds. Amsterdam: Kluwer, 1999, pp. 103-121.

18. L. Thalheim, J. Krissler, and P.-M. Ziegler, "Biometric Access Protection Devices and their Programs Put to the Test," Available online in c't Magazine, No. 11/2002, p. 114.

19. M. Kohn and M. Clynes, "Color dynamics of the pupil," Annals of New York Academy of Science, vol. 156, no. 2, 2006, pp. 931-950.

20. Pupil dynamics for iris liveness detection Adam Czajka, IEEE TRANSACTIONS ON INFORMATION FORENSICS AND SECURITY, VOL. 11, NO. 4, APRIL 2015

21. Trusted Biometrics under Spoofing Attacks (TABULA RASA). Project funded by the European Commission, under the Seventh Framework Programme. [Online]. Available: http://www.tabularasa-euproject.org

22. T. Matsumoto, "Artificial fingers and irises: Importance of vulnerability analysis," in Proceedings of the Seventh International Biometrics Conference and Exhibition, 2004.

23. Sinha V.K., Gupta A.K, Khanna R. , "Detection of Fake Iris by using Frame Difference and Reflection Ratio", I J C T A, 9(40) 2016, pp. 557-562

24. Sinha V.K., Gupta A., Mahajan M., "Detecting fake iris in iris bio-metric system", Digital Investigation (2018), https://doi.org/10.1016/j.diin.2018.03.002

25. Sinha V.K., Gupta A.K., "Enhancing Iris Security by Detection of Fake Iris". National Conference GyanJyoti-National Conference MITE. 2016. - P. 1-22. 


\section{AUTHORS PROFILE}

Dr. PankajBhambri received Ph.D. in Computer Science Engineering . He is working as Assistant Professor in the Department of Information Technology, Guru Nanak Dev Engineering College, Ludhiana (Punjab), His research area includes Image Processing, Neural Networks etc.

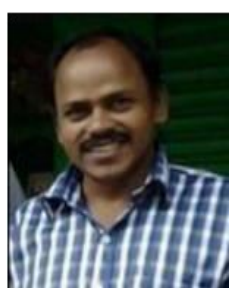

Vijay Kumar Sinha is a research scholar of IKGPTU, Kapurthala (Punjab). He received M.Tech. Degree in IT from Punjabi University, Patiala, Punjab (India) .He Received B.Tech. Degree from Thapar University, Patiala, Punjab (India).. He is serving for Chandigarh Engineering College, Landran, Mohalias Associate Professor since 10 years. His research interests includes Iris recognition, Biometric authentication, Image Processing, Fake biometric detection etc.

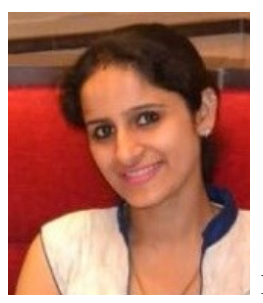

Ms. MeenakshiJaiswal is working as Assistant Professor at Chandigarh Engineering college, Landran, Mohali (Punjab), under IKG-PTU . She is M.Tech. in Computer Science \& Engineering. Her area of research interest includes software engineering, Software reuse, Green Computing and big data. She published a number of research papers in referred journals. 